\title{
LA-UR-97- \\ DIAMOND-LIKE CARBON PRODUCED BY PLASMA SOURCE ION IMPLANTATION AS A CORROSION BARRIER
}

R. SCOTT LILLARD, MST-6

DARRYL P. BUTT, MST-6

THOMAS N. TAYLOR, MST-6

K. C. WALTER, MST-8
RECEVED

MR 251998

OSTI

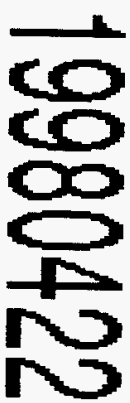

M. NASTASI, MST-8
Submitted to:

NACE CORROSION 1998 RESEARCH IN PROGRESS SYMPOSIUM TO BE HELD AT SAN DIEGO, CA ON MARCH 1998

\section{MASTER}

\section{Los Alamos}

NATIONAL LABORATORY

Los Alamos National Laboratory, an affirmative actionequal opportunity employer, is operated by the University of California for the U.S. Department of Energy under contract W-7405-ENG-36. By acceptance of this article, the publisher recognizes that the U.S. Government retains a nonexclusive, royalty-free license to publish or reproduce the published form of this contribution, or to allow others to do so, for U.S. Government purposes. The Los Alamos National Laboratory 


\section{DISCLAIMER}

This report was prepared as an account of work sponsored by an agency of the United States Government. Neither the United States Government nor any agency thereof, nor any of their en.ployees, makes any warranty, express or implied, or assumes any legal liability or responsibility for the accuracy, completeness, or usefulness of any information, apparatus, product, or process disclosed, or represents that its use would not infringe privately owned rights. Reference berein to any specific commercial product, process, or service by trade name, trademark, manufacturer, or otherwise does not necessarily constitute or imply its endorsement, recommendation, or favoring by the United States Government or any agency thereof. The views and opinions of authors expressed herein do not necessarily state of reflect those of the United States Government or-any agency thereof. 


\title{
Diamond-Like Carbon Produced by Plasma Source Ion Implantation as a Corrosion Barrier
}

\author{
R.S. Lillard, D.P. Butt, T.N. Taylor, K.C. Walter, M. Nastasi \\ Materials Science and Technology Division \\ The Los Alamos National Laboratory \\ Los Alamos, New Mexico 87545
}

\section{Introduction}

There currently exists a broad range of applications for which the ability to produce an adherent, hard, wear and, corrosion-resistant coating plays a vital role. These applications include engine components, orthopedic devices, textile manufacturing components, hard disk media, optical coatings, and cutting and machining tools (e.g., punches, taps, scoring dies, and extrusion dies). Ion beam processing can play an important role in all of these technologies.

Plasma source ion implantation (PSII) is an emerging technology which has the potential to overcome the limitations of conventional ion implantation by: (1) reducing the time and expense for implanting onto complex shapes and large areas and (2) extending the thickness of the modification zone through ion beam enhanced plasma growth of surface coatings. In PSII, targets are placed directly in a plasma source and then pulse biased to produce a non-line-of-sight process for complex-shaped targets without complex fixturing. If the pulse bias is a relatively high negative potential $(20$ to $100 \mathrm{kV}$ ) ion implantation will result. If however, a low voltage (50 $1200 \mathrm{eV}$ ) high duty cycle pulse bias is applied, film deposition from the chamber gas will result, thereby increasing the extent of the surface modification into the $1-10$ micron regime.

To evaluate the potential for DLC to be used as a corrosion barrier, Electrochemical Impedance Spectroscopy (EIS) and traditional electrochemistry techniques were used to investigate the breakdown mechanism in chloride and nonchloride containing environments(1). The effect of surface preparation on coating breakdown was also evaluated.

\section{Experimental}

High purity CVD Ni was made from the thermal decomposition of nickel carbonyl $\left(\mathrm{Ni}(\mathrm{CO})_{4}\right)$. The resultant CVD Ni samples were polished to a $0.30 \mu \mathrm{m}$ finish. These samples were then placed in an ion implantation chamber where the native oxide was removed by sputter etching with argon (Ar) for one hour. This sputter cleaning was immediately followed by carbon (C) implantation from methane at $30 \mathrm{kV}$. Carbon implantation prior to coating with DLC improves the adhesion properties of the DLC. After implantation, the surface was sputter cleaned for approximately 15 minutes. DLC was then deposited onto this surface from an RF plasma of acetylene to a thickness of approximately 4-5 microns(2).

The DLC coating produced by PSII had a density of $1.9 \mathrm{~g} / \mathrm{cm}^{3}$ and consisted of approximately 70 at $\mathrm{C}$ and 30 at\% hydrogen $(\mathrm{H})$. The $\mathrm{C}: \mathrm{H}$ ratio was found to greatly effect coating properties with lower hydrogen content yielding coatings with the highest hardness values. The $\mathrm{C}: \mathrm{H}$ ratio also effected coating resistivity and adhesion. The hardness of the DLC coatings examined was found to be to directly proportional to $\mathrm{sp} 3$ bonding content which varied between $55 \%$ and $20 \%$. Hardness values between 6 and $12 \mathrm{GPa}(3)$.

\section{Results and Discussion}

Characterization of DLC in Chloride Solution and EIS Model The EIS data of samples exposed to deaerated $0.25 \mathrm{M} \mathrm{NaCl}$ solution ( $\mathrm{pH} 7$ ), are presented in Figures 1 as a function of immersion time. As seen in Figure 1, three separate break point frequencies are observed in the Bode magnitude and phase data. While the low frequency data remain relatively unchanged during the $28 \mathrm{hr}$ immersion period, dramatic changes were measured in the frequency range $>10 \mathrm{~Hz}$. Upon removal from solution, large corrosion pits in the DLC could be easily seen. The EIS response in Figure 1 is best modeled by the equivalent circuit (EC) shown in Figure $2 b$. In this figure, the intrinsic electrical properties of the carbon implanted layer are represented by the elements $C_{1 L}{ }^{i}$ and $R_{1 L}{ }^{i}$, where the superscript ' $i$ ' represents "intrinsic" and are in units of farads $/ \mathrm{cm}^{2}$ in ohm $\mathrm{cm}^{2}$ respectively. This layer acts in series with the DLC coating represented by the 
elements $C_{D L C}{ }^{i}$ and $R_{D L C}{ }^{i}$ which model the capacitance and charge transfer resistance of the DLC. The elements representing the carbon implanted layer and DLC act in parallel with the elements representing small "pinholes" in the DLC. These pinholes (less than $20 \mu \mathrm{m}$ in diameter) expose either the carbon implanted layer, a very thin DLC layer or, a combination of both. The fraction of surface covered by these pinholes is defined by $\Theta$ and the fraction of surface covered by DLC is defined by $1-\Theta$. The parameters from the CNLS fitting of the DLC data are presented in Table 1 . As seen in this table, large changes in $\mathrm{R}_{\text {corr }}{ }^{\circ}$ (polarization resistance in ohms) were observed.

Properties of the $C$-implanted Layer Anodic polarization experiments for carbon implanted CVD Ni (without the DLC coating) in deaerated $0.25 \mathrm{M} \mathrm{NaCl}$ found active dissolution of the specimen at all potentials more positive than the OCP. Further, a positive hysteresis was observed upon reversal of the anodic potential scan indicating surface damage. While the unexposed surface was charcoal gray, the exposed surface was deep black. Scanning electron microscopy revealed that this exposed surface contained an extremely fine porosity not found in the unexposed surface.

$X$-ray photoelectron measurements of the unexposed and exposed surfaces revealed two very different concentrations of $\mathrm{Ni}$ as a function of depth (Figure 3a). For the unexposed sample the initial surface $\mathrm{C}$ concentration is more than 80 at.\% while that of $\mathrm{Ni}$ is less than 5 at\%. Between approximately 6 and 12 minutes of sputtering, the concentrations of both $\mathrm{C}$ and $\mathrm{Ni}$ level off near 50 at\%. The C KLL Auger transition lineshape (Figure $3 \mathrm{~b}$ ) over this sputtering range does not vary and, indicated a strong $\mathrm{Ni}$-carbide component(3). In contrast, during the first 16 minutes of sputtering in the exposed sample (Figure $4 \mathrm{a}$ ) the concentrations of both $\mathrm{C}$ and $\mathrm{Ni}$ remained close to their initial values. The C KLL Auger lineshape for the sample (Figure 4b) in this sputtering interval resembled that for graphitic or amorphous carbon $(4,5)$.

Collectively these results indicate that in $\mathrm{Cl}^{\circ}$ environment, the preferential dissolution of $\mathrm{Ni}$ from the implanted layer occurs at the OCP as well as at more anodic potentials. This process leaves behind a porous carbon rich layer with a graphitic amorphous bonding configuration. At the OCP this preferential dissolution likely owes to the galvanic interaction between $\mathrm{Ni}$-rich and $\mathrm{C}$-rich deposits in the implanted layer inside the defect. Because of restricted mass transport oxygen is depleted from the defect and separation of the anodic reactions in the defect and cathodic reaction on the boldly exposed DLC occurs. A galvanic couple is then established between the boldly exposed DLC and the $\mathrm{C}$ implanted $\mathrm{Ni}$ layer at the base of a defect. In the absence of $\mathrm{OH}^{-}$ production, $\mathrm{Cl}^{-}$migrates into the defect to maintain charge neutrality. This rise in $\mathrm{Cl}^{-}$concentration decreases the pitting potential of the $\mathrm{Ni}$ below the couple potential and allows the process to become autocatalytic once only $\mathrm{Ni}$ is exposed at the base of the defect.

\section{References}

1. R.S. Lillard, D.P. Butt, T.N. Taylor, K.C. Walter, M. Nastasi, Corr. Sci., vol. 9, pp. 1605-1624, 1997.

2. D.P. Butt, K.C. Walter, M. Nastasi, A.L. Campuzano, P.S. Martin, B.P. Wood, D.J. Rej, G.G. MIller, Philosophical Magazine Letters, vol. 70, pp. 385, 1994.

3. K.C. Walter, M. Nastasi, H. Kung, P. Kodali, C. Munson, I. Henins, B.P. Wood, in Materials Research Society Proceedings, vol. 383, 1995

4. J. P Coad and J. C. Rivière, Surf. Sci., vol. 25, pp. 33, 1971.

5. A. K. Green and V. Rehn, J. Vac. Sci. Technol., vol. Al, pp.1877, 1983.

Table 1 Select parameters from CNLS fitting of EIS data for DLC $\mathrm{Ni}$ in $0.25 \mathrm{M} \mathrm{NaCl}$ as a function of immersion time. Also presented is the \% area of the surface covered by defects $(\Theta)$.

\begin{tabular}{|c|c|c|c|c|c|c|}
\hline $\begin{array}{l}\text { Immersion } \\
\text { Time (hrs) }\end{array}$ & $\begin{array}{c}\mathbf{R}_{\text {corr }} \\
\text { (ohms) }\end{array}$ & $\begin{array}{c}\mathrm{C}_{\mathrm{d}}{ }^{\prime \prime} \\
\text { (Farads) }\end{array}$ & $\begin{array}{c}\mathbf{R}_{\mathrm{lL}}{ }^{\prime \prime} \\
\text { (ohms) }\end{array}$ & $\begin{array}{c}\mathrm{R}_{\mathrm{DLC}}{ }^{\prime \prime} \\
\text { (ohms) }\end{array}$ & $\begin{array}{c}\Theta \times 100 \\
\% \text { defect }\end{array}$ & $\begin{array}{c}(1-\Theta) \times 100 \\
\% \text { DLC }\end{array}$ \\
\hline 1 & $1.14 \times 10^{4}$ & $1.58 \times 10^{-8}$ & $1.13 \times 10^{+}$ & $5.89 \times 10^{11}$ & 0.003 & 99.997 \\
\hline 24 & $2.51 \times 10^{3}$ & $6.63 \times 10^{-3}$ & $1.13 \times 10^{4}$ & $1.44 \times 10^{12}$ & 0.02 & 99.98 \\
\hline 28 & 489 & $1.26 \times 10^{-1}$ & $1.07 \times 10^{4}$ & $2.91 \times 10^{6}$ & 0.08 & 99.92 \\
\hline
\end{tabular}




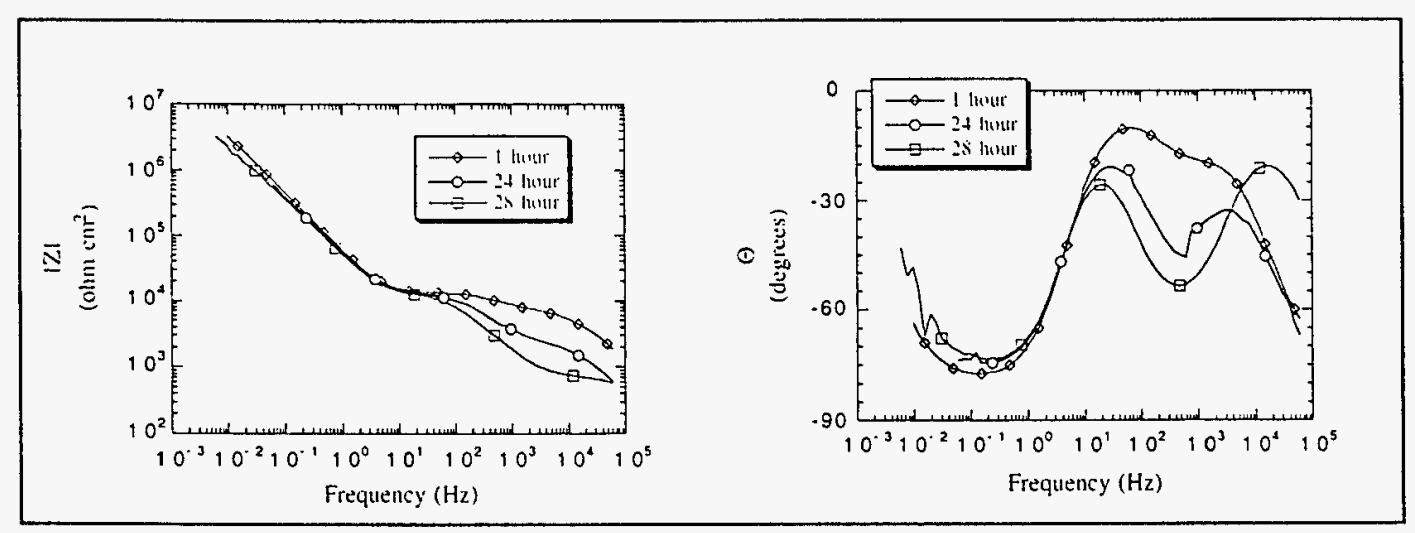

Figure 1 Bode a) magnitude and b) Bode phase plots for DLC coated CVD Ni in deaerated $0.25 \mathrm{M} \mathrm{NaCl}$ solution after I hr, $24 \mathrm{hrs}$, and 28 hrs of inmersion.

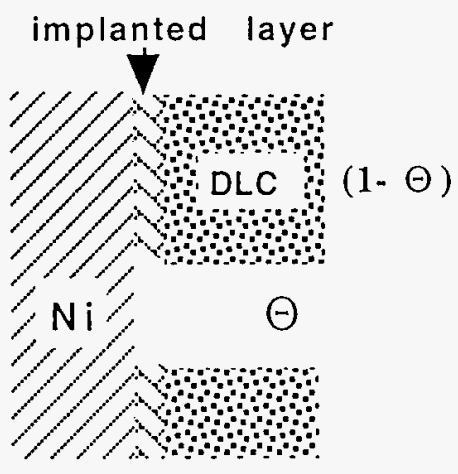

$\Theta$ pore surface coverage

$(1-\Theta)$ DLC surface coverage

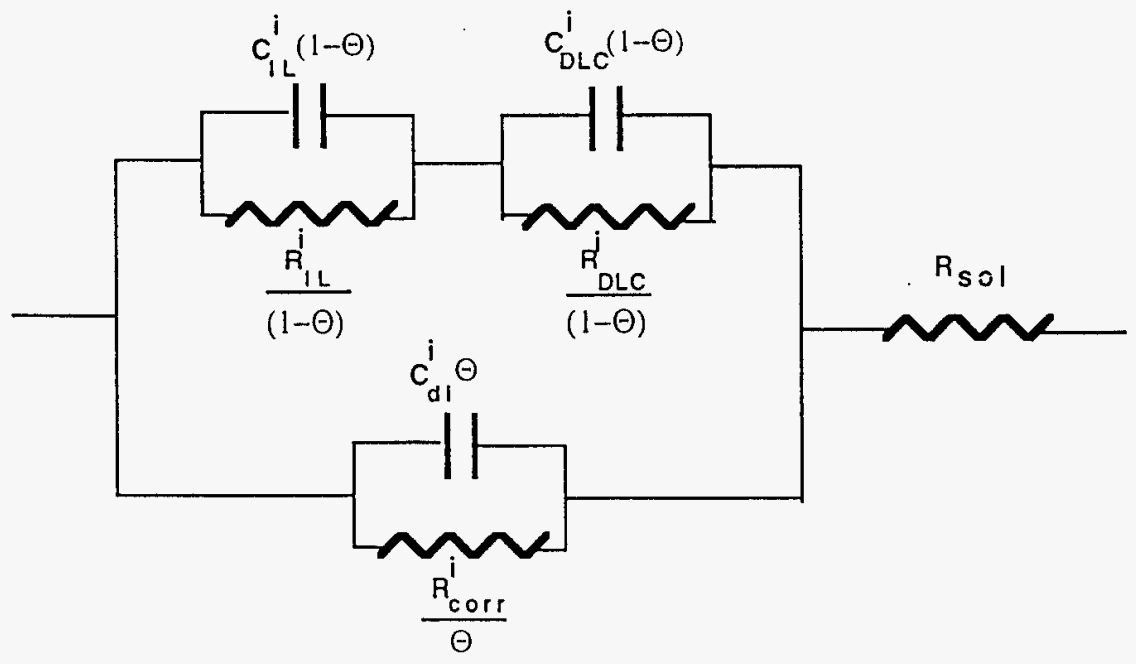

Figure 2 a) Schematic diagram representing the layers in DLC coating and a defect native to the coating b) electrical equivalent circuit model representing the breakdown of DLC coated CVD Ni in $\mathrm{NaCl}$ solution 

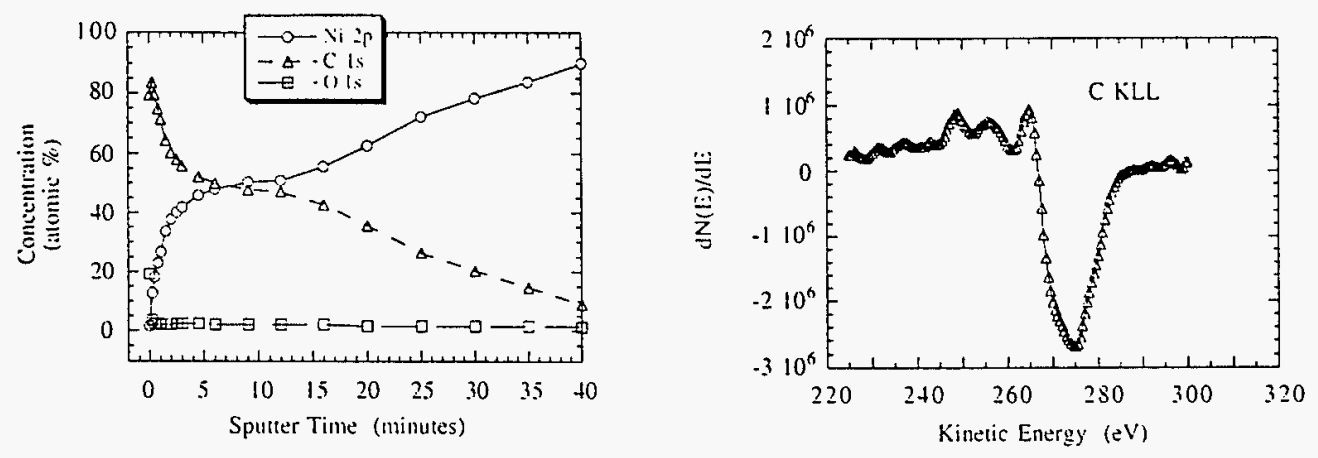

Figure 3 a) XPS sputter profile of carbon implanted CVD Ni prior to immersion in test solution. b) Auger line shape for C KLL on the same pre-immersion surface after 12 minutes of sputtering.
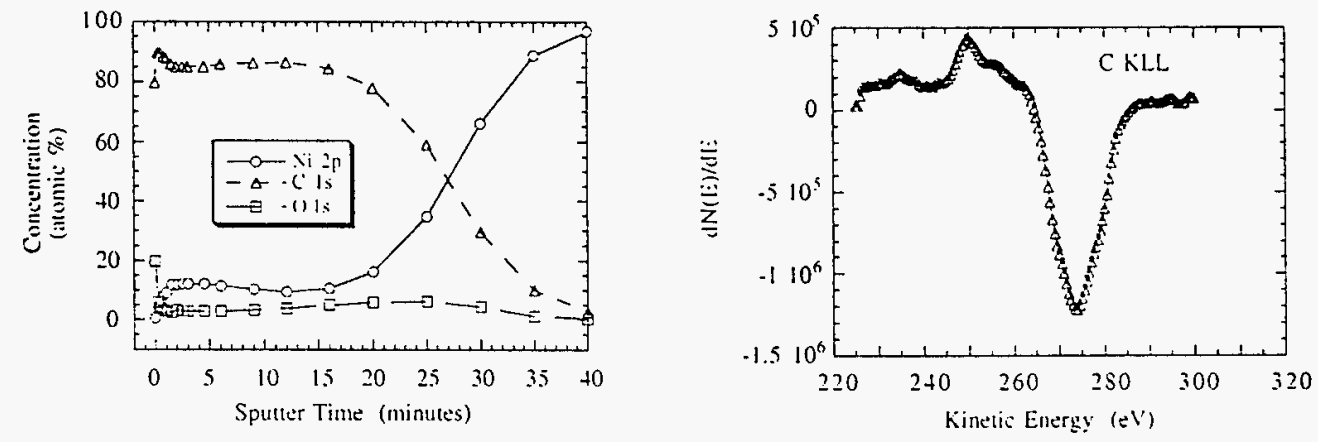

Figure 4 a) XPS sputter profile of carbon implanted CVD Ni after immersion and polarization in test solution. b) Auger line shape for C KLLon the same post-immersion surface after 12 minutes of sputtering.

\section{Acknowledgements}

The authors would like to thank G.G. Miller for supplying the CVD nickel and B.P. Wood and C.M. Munson for making the DLC coatings. Work on this project was funded under the auspices of the University of California for the U.S. Department of Energy contract number W-7405-ENG-36 
M98003305

M98003305

$\frac{\text { Report Number (14) }(A-4 P-97-4623}{\text { CONF-980316-二 }}$

Publ. Date (11) 199803

Sponsor Code (18) $\frac{D C}{U C} \mathrm{DP}, X F$
UC Category (19)
$\mathrm{WC}-704, D O E / E R$

DOE 